Société d'histoire de la révolution de 1848 et des révolutions du XIXe siècle

$41 \mid 2010$

L'Algérie au XIXe siècle

\title{
Eugène DELACROIX, Journal, nouvelle édition intégrale établie par Michèle Hannoosh, collection Domaine romantique, Paris, José Corti, 2009, 2 tomes, 2519 p. ISBN : 9782-7143-0999-0. 80 euros pour les deux volumes.
}

Nicole Edelman

\section{(2) OpenEdition \\ Journals}

Édition électronique

URL : http://journals.openedition.org/rh19/4058

DOI : $10.4000 /$ rh 19.4058

ISSN : $1777-5329$

Éditeur

La Société de 1848

Édition imprimée

Date de publication : 15 décembre 2010

Pagination : 154-155

ISSN : 1265-1354

Référence électronique

Nicole Edelman, «Eugène DELACROIX, Journal, nouvelle édition intégrale établie par Michèle Hannoosh, collection Domaine romantique, Paris, José Corti, 2009, 2 tomes, 2519 p. ISBN :

9782-7143-0999-0. 80 euros pour les deux volumes. », Revue d'histoire du XIXe siècle [En ligne], 41 I

2010, mis en ligne le 29 décembre 2010, consulté le 23 mars 2021. URL : http://

journals.openedition.org/rh19/4058; DOI : https://doi.org/10.4000/rh19.4058

Ce document a été généré automatiquement le 23 mars 2021

Tous droits réservés 


\title{
Eugène DELACROIX, Journal,
} nouvelle édition intégrale établie par Michèle Hannoosh, collection Domaine romantique, Paris, José Corti, 2009, 2 tomes, 2519 p. ISBN : 9782-7143-0999-0. 80 euros pour les deux volumes.

\author{
Nicole Edelman
}

Cette nouvelle édition, dans une belle collection de l'éditeur José Corti, du Journal de Delacroix qui n'avait pas été réédité depuis 1932, se fonde sur les manuscrits originaux et comporte de nombreux textes retrouvés par Michèle Hannoosh, qui dirige le département de langues et littératures romanes à l'université du Michigan (États-Unis) et qui présente ces deux volumes dans une longue introduction de 67 pages. Il s'agit donc bien d'une édition qui renouvelle celle d'André Joubin par de nombreux apports, en particulier de notes précédemment omises, d'annotations oubliées, d'inédits retrouvés, de carnets de voyages, de carnets de notes, de feuilles volantes, de projets d'articles, etc. Le journal lui-même débute le mardi 3 septembre 1822 et se termine le lundi 22 juin 1863, le tome un portant sur les années 1822-1857, le tome deux sur celles allant de 1858 à 1863, et comporte les suppléments formés de carnets, notes et fragments. L'ensemble est accompagné d'un appareil critique précieux, d'un répertoire biographique de tous les contemporains nommés dans le Journal, d'un appendice sur Eugénie Dalton (1802-1859) jusqu'alors mal connue, de généalogies précises de Delacroix, d'une bibliographie, d'un index des œuvres du peintre et des noms des personnes citées. 
2 L'édition, d'une grande qualité, est particulièrement précieuse pour les dixneuviémistes. Le Journal témoigne en effet non seulement de la vie publique et privée du peintre mais aussi de sa conception de l'art et de ses idées sur le monde et les hommes. Et Delacroix, « le peintre-poète » comme l'appelait Baudelaire, développe tout cela avec un talent d'écrivain. Il commente donc, au jour le jour, ses activités et ce qu'il voit, entend, regarde de la société qui l'entoure. Or le peintre y occupe une place très particulière, «d'une part accepté dans des cercles officiels, jouissant d'une certaine faveur de l'État, membre, enfin en 1857, de l'Institut; d'autre part, peintre encore contesté, familier d'écrivains et d'artistes à leur manière "scandaleux » comme Baudelaire ou Georges Sand, acclamé par la jeunesse radicale - cette position le mettait en contact avec toute la gamme des personnages de son temps » (Michèle Hannoosh, p. 33). Et en effet, à lire l'index des personnes, c'est tout le XIX ${ }^{e}$ siècle qui se profile. Delacroix visite les salons dont il est parfois membre du jury, fréquente la haute société (23 mars 1854: «Bal aux Tuileries : même sentiment d'ennui des autres et de moimême. Cette abjection dorée est la plus triste de toutes ", p. 741). Il est aussi amateur de musique (Chopin est son ami), de théâtre et d'opéra, dont il commente les œuvres, leurs réalisations et leurs décors. Il s'intéresse bien sûr à la peinture mais aussi à la photographie et il est un lecteur curieux des romans de ses contemporains français et étrangers. Michèle Hannoosh a retrouvé le catalogue de vente d'une partie de la bibliothèque de Delacroix, où l'on trouvait Dumas, Sand, Balzac, Baudelaire, Gautier, Dickens, Emerson, Hawthorne, Poe, Tourgueniev et d'autres encore. Delacroix lit aussi régulièrement la plupart des grands journaux français : Le Moniteur, La Presse, Les Débats, Le Constitutionnel, etc.et plusieurs revues: La Revue des Deux Mondes, La Revue de Paris, L'Illustration, Le Magasin pittoresque, La Revue britannique. Il multiplie les réflexions sur tous ces sujets, sur son siècle et le temps qui passe ( 21 octobre 1859 : «Toutes les révolutions mettent en fièvre les natures basses et prêtes à mal faire. Les âmes traîtresses posent le masque; elles ne peuvent se contenir à la vue du désordre universel qui semble leur offrir des proies à saisir ", p. 1347). Il propose des tableaux d'une vie quotidienne au XIXe siècle à Paris et à Champrosay mais aussi en Afrique du Nord et en Andalousie où il a, on le sait, voyagé : Meknès, Fouarate, Alcassar-El-Kebir, Tanger et Séville, etc. Il est toujours fort attentif aux lumières et aux couleurs, à celle des corps ( 7 septembre 1856 : «La chair n'a sa vraie couleur qu'en plein air et surtout au soleil. Qu'un homme mette la tête à la fenêtre, il est tout autre que dans l'intérieur ; de là la sottise des études d'atelier, qui s'appliquent à rendre cette couleur fausse ", p. 1034). La qualité de cette édition du Journal de Delacroix met donc entre les mains du lecteur en général et de l'historien en particulier, un véritable fonds d'archives aux multiples lectures possibles. 